\title{
QUEIJO ARTESANAL SERRANO NOS CAMPOS DE CIMA DA SERRA (RS): ANÁLISE DA DIMENSÃO INSTITUCIONAL DE UM SISTEMA AGROALIMENTAR LOCALIZADO
}

\author{
Lilian Varini Ceolin ${ }^{1}$ \\ Leonardo Alvim Beroldt da Silva ${ }^{2}$ \\ Larissa Bueno Ambrosini ${ }^{3}$
}

\begin{abstract}
RESUMO
O Queijo Artesanal Serrano (QAS) é produzido há mais de 200 anos nos Campos de Cima da Serra, no sul do Brasil, de modo tradicional, por produtores familiares, a partir de leite cru. O QAS é um produto de relevância histórica, social e econômica para a região. Sua produção, entretanto, enfrenta dificuldades com relação aos marcos legais. O objetivo desse estudo é analisar o ambiente institucional de produção do QAS sob a perspectiva dos Sistemas Agroalimentares Localizados (SIAL). Através de aplicação de roteiros semiestruturados, foram avaliadas as relações interinstitucionais e alterações ocorridas nos últimos 10 anos. Existe uma multiplicidade de atores envolvidos, sendo que a apresentação da mobilização coletiva em torno do produto leva a definição de um SIAL na forma passiva.
\end{abstract}

Palavras-chave: Instituições, produtos artesanais, produtos tradicionais.

\section{SERRANO ARTISANAL CHEESE IN CAMPOS DE CIMA DA SERRA, RS, BRAZIL: AN ANALYSIS BY THE INSTITUTIONAL DIMENSION OF LOCATED AGRI-FOOD SYSTEMS}

\begin{abstract}
Artisanal Serrano Cheese (QAS) has been produced for over 200 years, in southern Brazil, by family producers, from raw milk. The QAS is a product of historical, social and economic relevance for the region. Its production, however, faces difficulties in relation to legal frameworks. The aim of this study is to analyze the institutional production environment of the QAS from the perspective of Localized Agrifood Systems (SIAL). Through the application of semi-structured scripts, interinstitutional relations and changes that occurred in the last 10 years were evaluated. There is a multiplicity of actors involved, and the presentation of collective mobilization around the product leads to the definition of a SIAL in passive form.
\end{abstract}

Key words: Institutions, artisanal products, traditional products

\footnotetext{
1 Graduada em Medicina Veterinária (UFSM). Mestre em Ambiente e Sustentabilidade (UERGS). Extensionista Rural (Emater/RS). E-mail: lilaceolin@gmail.com.

${ }^{2}$ Graduado em Agronomia (UFRGS). Mestre em Fitotecnia (UFRGS). Doutor em Desenvolvimento Rural (UFRGS). Professor Adjunto (UERGS). E-mail: beroldt@gmail.com.

${ }^{3}$ Graduada em Medicina Veterinária (UFRGS). Mestre em Desenvolvimento Rural (UFRGS). Doutora em Sciences de Gestion (UB-França). Pesquisadora (DDPA-SEAPDR/RS). E-mail: larissabueno@gmail.com.
} 


\section{INTRODUÇÃO}

Há mais de 200 anos, nos campos de altitude dos estados do Rio Grande do Sul (RS), denominados Campos de Cima da Serra (CCS), e de Santa Catarina (SC), denominado Planalto Catarinense, no sul do Brasil, é realizada a produção de um queijo artesanal característico da região, denominado Queijo Serrano ou Queijo Artesanal Serrano (QAS). O queijo é produzido por produtores familiares, a partir de leite cru, ordenhado de vacas de raças cruzadas de corte, alimentadas com pasto nativo (CRUZ; SANTOS, 2016). A produção é individual, acontece em cada uma das propriedades distribuídas pelo território, e é feita apenas com o leite produzido na própria unidade (AMBROSINI; FILIPPI, 2008).

A produção do QAS é desenvolvida a partir de uma cultura constituída, primordialmente, em torno da atividade de criação de bovinos para engorda; e não em uma região caracterizada por constituir-se em uma bacia leiteira, de onde decorre uma singularidade importante (AMBROSINI; FILIPPI, 2008). Este produto preserva, desde sua origem, as características físicas e organolépticas dadas pelo microclima da região e as técnicas tradicionais de produção (KRONE; MENASCHE, 2010).

Ao longo de sua trajetória histórica, o QAS tem sido um alimento de subsistência, mesclado com outras atividades para compor as receitas das propriedades rurais. Durante o ciclo do tropeirismo, era carregado no lombo de mulas, juntamente com couro, crina e charque e utilizado como moeda de troca por produtos que não eram produzidos na região (VELHO et al., 2011). Já nos últimos anos, a produção de queijo aparece como uma fonte de renda importante para as famílias. Em estabelecimentos com até 200 hectares, o queijo pode representar até $50 \%$ da renda bruta anual (AMBROSINI, 2007). O acesso ao mercado, entretanto, acontece diferentemente, conforme a localização geográfica dos produtores, mas, também, segundo relações mantidas e constituídas ao longo do tempo com seus compradores (AMBROSINI; FILIPPI, 2008).

Segundo Ries et al. (2012), apenas no RS, estima-se em 1.500 o número de famílias produtoras de QAS. De acordo com o autor, apesar de sua importância, a produção ocorre geralmente na informalidade, colocando tanto os produtores quanto os consumidores em situação de insegurança. Para os consumidores não há garantia de estar adquirindo o legítimo QAS, nem garantia sobre a qualidade sanitária do produto. Os produtores, por outro lado, são tratados como transgressores ou criminosos por venderem um produto artesanal, tal como seus antepassados faziam. Entretanto, a relação de confiança do consumidor com o produtor de QAS permanece mais forte do que as exigências legais, se constituindo em uma verdadeira instituição.

Mesmo caracterizado por um saber-fazer já consolidado, e possuindo legislação própria aprovada no RS, atualmente o número de produtores de QAS com agroindústrias regularizadas é inexpressivo. Durante a realização desta pesquisa, de outubro a dezembro de 2018, duas agroindústrias de QAS estavam trabalhando dentro do sistema de inspeção, mas já foram mais 20 nessa situação, segundo a Associação Riograndense de Empreendimentos de Assistência Técnica e Extensão Rural (Emater/RS). Este decréscimo deu-se principalmente porque os marcos legais exigidos não condizem com a forma de produção preponderante. A estrutura física requerida para as queijarias e o tempo de maturação mínimo de 60 dias, conforme indica a Instrução Normativa no 07, de 9 de dezembro de 2014, são os principais limitantes (RIO GRANDE DO SUL, 2014c). De acordo com Führ et al. (2019), há 
necessidade de avanços na regulamentação para a produção e venda de alimentos artesanais, sendo ressaltados impasses econômicos, culturais, ambientais e sociais, em função de sua pequena escala de produção.

$O$ interesse por alimentos artesanais e tradicionais aparece como uma tendência, e está inserida num contexto de demanda crescente por alimentos naturais, menos processados, com características únicas, ou diferenciadas. Estudar - QAS sob a perspectiva dos Sistemas Agroalimentares Localizados (SIAL), pode apresentar como resultado um exemplo de resistência do modo de fazer tradicional apesar das dificuldades que se impõe sobre a regularização da produção de alimentos artesanais no Brasil.

A noção de SIAL foi desenvolvida em um contexto de crise das sociedades rurais, de piora dos problemas ambientais e dos novos desafios alimentares colocados às diferentes sociedades, tanto quantitativa como qualitativamente. A primeira definição foi apresentada para buscar compreender os agrupamentos geográficos das empresas agroalimentares que resistiram ou inovaram, utilizando estratégias locais de desenvolvimento de recursos e produtos (MUCHNIK et. al., 2007). O enfoque proposto para análise de um SIAL, de acordo com Muchnik (2006), apresenta como guia quatro dimensões de base: (i) dimensão histórica; (ii) dimensão técnica; (iii) dimensão institucional e (iv) dimensão alimentícia.

A dimensão histórica é uma das principais bases para a análise, pois permite compreender a relação do produto com seu contexto ambiental, social e econômico ao longo do tempo. A dimensão técnica é centrada na observação, na descrição e na análise dos saberes e de técnicas utilizadas para a condução de um sistema de cultivo, de criação ou a transformação de um produto alimentar. O que é interessante averiguar é a capacidade de replicação desse conhecimento em outros contextos. Também é importante observar como ocorrem os processos de transmissão de determinados conhecimentos, via tradição familiar, ou dentro da comunidade, se os mesmos vêm sendo interrompidos, ou transformando-se (SPECHT, 2009).

A dimensão institucional refere-se às relações entre os atores sociais, suas estratégias individuais e coletivas (MUCHNIK, 2006). Além disso, é fundamental analisar o poder estruturante do Estado, suas regras e poderes (RUCKERT, 2004). Para operacionalizar metodologicamente esta dimensão, convém observar as relações que se estruturam em nível local, através da observação de vínculos sociais (SPECHT, 2009).

A dimensão alimentícia focaliza as interações sociais, culturais e econômicas que ocorrem entre o produto e o consumidor. Em geral os produtos do SIAL são diferenciados na sua origem pelas características intrínsecas restritas a um ambiente produtivo específico e, se reconhecidas, passam a ser apreendidas como valor simbólico, extrapolando a relação monetária de custo versus benefício (SPECHT, 2009).

O QAS, utilizando como ferramenta o enfoque SIAL, foi estudado por Ambrosini (2007). A autora realizou um importante levantamento sobre o desenvolvimento da produção do QAS nos Campos de Cima da Serra definindo a paisagem, o modo de vida de seus produtores, cuja identidade está relacionada à bovinocultura de corte, tendo o QAS como fonte de renda relevante.

A conformação de um SIAL passa pela identificação dos atores, bem como de suas relações, às quais serão condicionadas por laços de proximidade e pertencimento a um espaço, sendo composto por relações horizontais e verticais.

[...] a verticalidade diz respeito aos processos envolvidos até a comercialização e remuneração do produto no mercado 
consumidor. As relações horizontais, por outro lado, se apresentam no nível territorial, envolvendo atividades agrícolas e não-agrícolas, instituições locais, saberes locais, entre outros. O que as une, ou constitui o ponto nodal de cruzamento entre as relações à jusante e à montante e as horizontalidades, é o território. (AMBROSINI, 2007, p.90-91)

Decorridos 10 anos do estudo de Ambrosini (2007), percebemos mudanças, tais como desenvolvimento de legislação específica e de novas organizações sociais, os processos de reconhecimento do "saber-fazer" do QAS como patrimônio imaterial, o processo de demanda da indicação geográfica. No entanto, esses avanços parecem não ser suficientes para estimular processos de formalização de unidades produtoras de QAS. Isso justifica a volta a este tema, aprofundando aspectos que à época não foram abordados.

Diante deste cenário, o presente estudo teve como objetivo analisar a relação entre instituições ligadas direta ou indiretamente a esta organização produtiva, além de identificar eventuais mudanças ocorridas no decorrer do tempo. O artigo está organizado da seguinte forma: na seção dois será abordado o território de produção do QAS, na seção três, será apresentada a metodologia de coleta dos dados, os quais serão analisados na seção quatro, na seção cinco propomos uma análise comparativa do contexto produtivo atual e daquele verificado 10 anos atrás; por fim tecemos considerações finais.

\section{TERRITÓRIO DO QUEIJO ARTESANAL SERRANO}

Estudar O QAS sob a perspectiva do Sistema Agroalimentar Localizado (SIAL) traz consigo uma relação direta com território, ponto de cruzamento entre as relações horizontais e verticais dos atores. O conceito de "território" tem distintos significados e interpretações, de tal maneira que seu uso está difundido em diferentes áreas de conhecimento. Apesar da diversidade, no entanto, existem elementos comuns nas definições e aplicações do conceito: (i) refere-se a um espaço de identidade social, cultural ou econômica, que não se restringe a limitações político administrativas; (ii) relaciona o espaço com atributos ou recursos específicos, como os atores e os recursos territoriais (BOUCHER, 2013).

Além disso, pode servir de referência para intervenção de políticas públicas e projetos de desenvolvimento, por ser flexível em seus limites, diferentemente de outras unidades geográficas de administração pública, como por exemplo, um estado, município ou distrito. Coloca ainda em evidência os atributos ambientais, condicionando a dinâmica das atividades produtivas e agropecuárias ao binômio território-ambiente (BOUCHER, 2013).

O território onde o QAS é produzido foi determinado com base em fatores culturais e geográficos como relevo, clima, altitude e vegetação, por intermédio de estudos realizados pela Emater/RS e Empresa de Pesquisa Agropecuária e Extensão Rural de Santa Catarina (Epagri), totalizando 16 municípios no RS e 18 em SC, na região sul do Brasil. A Lei no 14.973/2016, que dispôs sobre a produção e a comercialização do QAS, define como a região produtora no RS os seguintes municípios: André da Rocha, Bom Jesus, Cambará do Sul, Campestre da Serra, Capão Bonito do Sul, Caxias do Sul, Esmeralda, Ipê, Jaquirana, Lagoa Vermelha, Monte Alegre dos Campos, Muitos Capões, Pinhal da Serra, São Francisco de Paula, São José dos Ausentes e Vacaria (RIO GRANDE DO SUL, 2016).

O ambiente de produção do QAS apresenta um clima temperado, com $77 \%$ da altitude na faixa de 700 a $1.100 \mathrm{~m}$ e pontos com até $1.822 \mathrm{~m}$ e solos 
diversificados. A paisagem é formada por florestas de araucárias, rios, cachoeiras, vales, campos de altitude e grandes cânions. Os solos são rasos a pouco profundos na maior parte, e com baixa fertilidade natural, com afloramento de rochas, e relevo de ondulado a fortemente ondulado, tendo os solos dominantes normalmente ácidos (VIEIRA, 2017). A umidade relativa do ar fica em torno de $80 \%$ ao longo do ano, com baixas temperaturas, sendo que as médias anuais ficam em torno de $14^{\circ} \mathrm{C}$, com precipitação anual em média de $2.000 \mathrm{~mm}$ bem distribuída ao longo do ano (STRECK et al., 2018). São abundantes os mananciais de águas límpidas, com extensas coxilhas de campos nativos, predomínio do capim caninha (Andropogon lateralis NEES), emoldurados por capões de mato, com grande ocorrência de Araucária (Araucaria angustifólia (BERTOL, KUNTZE, 1898; VELHO et al., 2011).

Os municípios participantes deste estudo foram selecionados de acordo com levantamento fornecido pela Emater/RS referente ao número de produtores de QAS de cada um dos 16 municípios que compõem o território no RS. Os cinco municípios com maior número de produtores de QAS neste território, e visitados neste trabalho, são, em ordem decrescente: Bom Jesus, São José dos Ausentes, São Francisco de Paula, Jaquirana e Cambará do Sul. É comum a estes municípios possuir base da economia na agropecuária, baixa densidade populacional e infraestrutura de acessos precária, em função das grandes distâncias. Os dados de área total dos municípios e a respectiva população total, rural e urbana, além do número estimado de produtores de QAS estão apresentados na Tabela 1:

Tabela 1 - Dados dos principais municípios produtores de QAS.

\begin{tabular}{|c|c|c|c|c|c|}
\hline \multirow{2}{*}{ Município } & \multirow{2}{*}{$\begin{array}{l}\text { Área } \\
(\mathrm{em} \\
\left.\mathrm{Km}^{2}\right)^{1}\end{array}$} & \multicolumn{4}{|c|}{ № de habitantes } \\
\hline & & $\begin{array}{l}\text { População } \\
\text { total }^{1}\end{array}$ & $\begin{array}{l}\text { População } \\
\text { urbana }^{1}\end{array}$ & $\begin{array}{l}\text { População } \\
\text { Rural }^{1}\end{array}$ & $\begin{array}{l}\text { Produtores } \\
\text { de } \text { QAS }^{2}\end{array}$ \\
\hline Bom Jesus & 2624.67 & 11519 & 8593 & 2926 & 229 \\
\hline $\begin{array}{l}\text { São José dos } \\
\text { Ausentes }\end{array}$ & 1173.95 & 3290 & 2062 & 1228 & 125 \\
\hline $\begin{array}{l}\text { São Francisco } \\
\text { de Paula }\end{array}$ & 3272.98 & 20537 & 13004 & 7533 & 73 \\
\hline Jaquirana & 907.94 & 4177 & 2430 & 1747 & 62 \\
\hline $\begin{array}{l}\text { Cambará do } \\
\text { Sul }\end{array}$ & 1208.65 & 6542 & 3041 & 3501 & 33 \\
\hline
\end{tabular}

\section{MÉTODOS}

A primeira fase da pesquisa, de setembro de 2017 a fevereiro de 2018 , foi composta por coleta de dados secundários, além de informações fornecidas pela Emater/RS, agentes chave na comunidade. Através desses dados, foi possível conhecer melhor o campo empírico e construir os questionários aplicados na segunda etapa, objetivando analisar as percepções e relações entre instituições ligadas ao SIAL do QAS, assim como possíveis mudanças no decorrer do tempo, partindo dos resultados do trabalho de Ambrosini (2007).

Em março de 2018, na segunda fase da pesquisa, foram entrevistados um extensionista rural da Emater/RS de cada um dos cinco municípios (Bom Jesus, São José dos Ausentes, São Francisco de Paula, Jaquirana e Cambará do Sul). De 
outubro a dezembro do mesmo ano, foram entrevistados quatro prefeitos e um viceprefeito, assim como os secretários de agricultura destes municípios. Também foram entrevistados os médicos veterinários dos sistemas de inspeção municipal dos cinco municípios, totalizando sete profissionais. Além destes, foram entrevistados o assistente técnico estadual na área do leite da Emater/RS, duas pesquisadoras estudiosas do tema ligadas a universidades, presidente de Sindicato Rural, médico veterinário de Inspetoria Veterinária, um ex-extensionista da Emater/RS e os presidentes das associações de produtores de QAS deste território (Associação dos Produtores de Queijo Serrano e Laticínios dos Campos de Cima da SerraAprocampos, Associação de Produtores de Queijo de Jaquirana e Cambará do SulAprojac, e Associação de produtores de Queijo Artesanal Serrano e demais estabelecimentos de produtos de origem animal de São Francisco de PaulaAprosãochico), além do vice-presidente da Aprocampos, e um chef de cozinha de origem local, totalizando 33 entrevistados.

Pela dificuldade de deslocamento, foram contatados entre os meses de outubro a dezembro de 2018 via e-mail, o assistente técnico regional da Emater/RS da área de criações, dois representantes da Secretaria de Desenvolvimento Rural do RS (SDR), dois representantes da Secretaria da Agricultura, Pecuária e Irrigação do RS (SEAPI), um representante do Ministério da Agricultura, Pecuária e Abastecimento do Brasil (MAPA), o consultor técnico do Programa de "Qualificação da Cadeia do QAS", uma pesquisadora ligada à universidade, um pesquisador da Epagri, totalizando nove entrevistados.

Com o objetivo de preservar a identidade dos entrevistados, no decorrer do texto, as falas foram citadas abrangendo grupos: Técnico (a) de extensão rural (Emater/RS e Epagri), Pesquisador (a) (universidades e SEAPI), Gestor (a) municipal (Prefeitos, vice-prefeito e secretários da agricultura), Fiscal (Médicos (as) veterinários (as) dos SIM, MAPA, SDR, SEAPI, Consultor técnico), Representante de produtores rurais (Aprocampos, Aprojac, Aprosãochico, Sindicato Rural).

\section{A DIMENSÃO INSTITUCIONAL DO SIAL}

$\mathrm{Na}$ concepção de North (1990), as instituições são regras formais e informais que se destinam a regular as interações sociais, sendo seu papel principal a redução de incertezas ao prover uma estrutura que orienta as trocas. A regras informais são estabelecidas pelas características culturais, pela tradição, e não precisam ser codificadas; podem existir apenas nas mentes das pessoas. As regras informais podem ser suplementares às regras formais e até mesmo modificá-las, razão que as tornam mais duradouras.

Segundo Lascoumes (2014), as instituições são os procedimentos, as convenções, as formas de organização, as tecnologias, mas também as crenças, os esquemas intelectuais e os conhecimentos que envolvem, sustentam, interpretam ou contradizem as rotinas e os papéis. Existe uma definição mais ampla do conceito de instituições, incluindo linguagem, dinheiro, empresas e outras organizações:

[...] Institutions are durable systems of established and embedded social rules that structure social interactions. Language, money, systems of weights and measures, table manners, firms (and other organizations) are all institutions. In part, the durability of institutions stems from the fact that they can usefully create stable expectations of behavior of others. Generally, institutions enable ordered thought, expectation and 
action, by imposing form and consistency on human activities. They depend upon the thoughts and activities of individuals but are not reducible to them. (HODGSON apud CONCEIÇÃO, 2002, p.125)

O queijo artesanal é um produto regido tanto pela tradição quanto por normas legais e coletivas, sendo que a tradição rege o modo de fazer do queijo e tem sido passado de pai para filho a cada geração:

[...] as normais legais determinam os cuidados higiênicos e sanitários a serem observados para a salvaguarda da saúde pública; e as normas coletivas ou convenções vêm agregar valor ao queijo para atender às exigências de qualidade $e$ necessidades do mercado consumidor, em conformidade com a eficiência no processo produtivo que proporcione melhorias na qualidade de vida dos produtores. Falar desse produto, que é de domínio da coletividade, implica falar nas instituições informais, formais e coletivas, ou seja, na tradição, na legislação aplicada ao produto e nas convenções coletivas que o regem (FRANÇA, 2012, p.74).

A dimensão institucional do SIAL procura analisar as relações entre os atores, através de suas estratégias individuais e coletivas (MUCHNIK, 2006). A consciência da multiplicidade de atores envolvidos em processos localizados, bem como sua complexidade, ligados em especial à diferenciação de funções e às relações entre diferentes grupos é que faz emergir a abordagem do SIAL (REQUIER-DESJARDINS, 2010).

Ambrosini (2007) descreve que as figuras que compõem basicamente a cadeia de produção e distribuição do QAS são produtores rurais, intermediários, pontos de comércio e consumidores, sendo que os criadores de gado são os mesmos queijeiros, concentrando em si a produção de matéria prima e seu processamento. Entretanto, a dimensão institucional do SIAL abriga diversas instituições. Portanto, neste trabalho de pesquisa, buscamos entrevistar representantes das associações de produtores, gestores municipais, órgãos de inspeção de produtos de origem animal, serviço de extensão rural, entidades de pesquisa, entre outros.

\subsection{A ATUAÇÃO DO PODER PÚBLICO NO PROCESSO DE PRODUÇÃO}

Em relação à percepção sobre a atuação do poder público no processo de produção e comercialização do QAS, constatamos que a implantação e estruturação dos Sistemas de Inspeção Municipal (SIM), com enfoque fiscalizatório e de orientação, foi o ponto recorrente em nossas entrevistas. Todos os municípios do estudo apresentaram legislação de instalação dos respectivos SIM (BOM JESUS, 1995; CAMBARÁ DO SUL, 2004; SÃO FRANCISCO DE PAULA, 2007; SÃO JOSÉ DOS AUSENTES, 2007; JAQUIRANA, 2016). Entretanto, em novembro de 2018, dos 16 municípios que compunham o território do QAS no RS, somente sete municípios, incluindo os deste estudo, apresentavam estruturação mínima atrelada a uma sinergia de trabalho por parte da assistência técnica oficial do Estado (Emater/RS), verificando-se assim deficiências operacionais que carecem de atenção.

Além disso, convergiram afirmações sobre obtenção de recursos via Consulta Popular (RIO GRANDE DO SUL, 1998), através do Fundo Estadual de 
Apoio ao Desenvolvimento dos Pequenos Estabelecimentos Rurais (FEAPER) (RIO GRANDE DO SUL, 2017), ponto fundamental para viabilização do investimento em estrutura física das queijarias e equipamentos. Sem esta possibilidade de aporte de recursos, dificilmente os produtores teriam condições para realizar este tipo de investimento.

O convênio firmado entre prefeituras e Emater/RS para a realização de atividades de educação, visitas às propriedades e incentivo aos produtores também foi mencionado. Destacou-se também o apoio na esfera federal ao processo da Indicação Geográfica (IG) e viabilização de recursos para projetos de pesquisa e extensão, e, no âmbito estadual, regulamentação de legislação (RIO GRANDE DO SUL, 2010; 2014a; 2014b; 2014c; 2016; 2018).

Entre as divergências está a melhoria dos acessos às propriedades de produtores de QAS, com gestores municipais destacando a disponibilidade de cascalho e maquinários pelas Secretarias de Obras dos municípios, e produtores queixando-se dos problemas de manutenção dos acessos às propriedades rurais.

\subsection{POSSIBILIDADES DE AÇÕES DOS GESTORES PÚBLICOS COMO POLITIICAS AFIRMATIVAS AO QUEIJO ARTESANAL SERRANO.}

Sobre as possibilidades de atuação do poder público, houve convergência de respostas acerca da necessidade de avanço em legislações específicas para produtos artesanais. Foi reforçada a preocupação com redução do tempo legal de maturação do produto, que, segundo a normativa vigente para queijos produzidos a partir de leite cru, estabelece o mínimo de 60 dias.

Gestores públicos citaram a possibilidade do pagamento de profissional responsável técnico como fomento às agroindústrias. Além disso, apoio para o pagamento de análises laboratoriais dos produtos conforme exigência das legislações de inspeção. Também a criação de política pública que fomenta a testagem dos rebanhos para tuberculose e brucelose, e indenização de animais positivos que necessitam ser abatidos - já que a maior parte dos produtores de QAS não é atendida no Programa Nacional de Controle e Erradicação da Brucelose e da Tuberculose Animal (PNCEBT).

Apesar da maior parte das agroindústrias de QAS necessitarem de apoio financeiro para sua organização inicial principalmente em relação à construção e aquisição de equipamentos, este tipo de política de investimento com recurso público para as demais atividades de rotina pode gerar uma dependência que fragiliza a autonomia e profissionalização destes produtores.

Para os agentes ligados aos Sistemas de Inspeção Municipal deveria haver uma maior atuação da Vigilância Sanitária dos municípios. A contratação de mais técnicos para dar suporte de orientação e fiscalização foi mencionada como necessária dada dificuldade atual de atendimento das demandas dos municípios. Outra sugestão foi o aumento de ações voltadas para pesquisa técnica na área de qualidade do QAS.

\subsection{PRINCIPAIS DIFICULDADES EM RELAÇÃO À ADEQUAÇÃO DA PRODUÇÃO DO QUEIJO ARTESANAL SERRANO À LEGISLAÇÃO VIGENTE.}

Entre os principais entraves citados pelos produtores para adequação do QAS à legislação está o período de maturação, porque exige aumento de estrutura para guarda dos queijos. O período mais longo também demanda capital de giro aos produtores, dada a escala reduzida de produção. Além disso, segundo os 
produtores, os consumidores do QAS, em sua maioria, não apreciam o queijo maturado acima de 60 dias, preferindo queijos de 10 a 15 dias de maturação.

Entretanto, para os pesquisadores, a regulamentação que foi construída não seria o entrave maior (sanitário), mas, sim, as políticas de inclusão. De acordo com os mesmos, há alguns anos a legislação sanitária era um empecilho, sendo que a barreira de utilização de leite cru para a produção de queijo foi vencida. A continuidade de estudos em relação ao QAS é fundamental para que seja possível avançar em relação ao padrão de qualidade do produto, que é diferente de produtos industriais produzidos a partir de leite pasteurizado. É possível que as avaliações microbiológicas que estão sendo exigidas pela legislação (Salmonella spp., Listeria monocytogenes, estafilococos coagulase positivo e coliformes a $45^{\circ} \mathrm{C}$ ) não correspondam aos principais riscos sanitários deste produto.

Além disso, a dificuldade de compreensão do produtor sobre as exigências legais e entraves culturais foi destacada. $O$ fato de ser fiscalizado foi visto como uma barreira, pois os produtores sentem-se intimidados com esse processo. Há ainda dificuldade para atender as exigências dos SIM, devido à falta de uniformidade na atuação dos diferentes agentes de inspeção. A falta de padrão na interpretação dos fiscais gera insegurança aos produtores, segundo um dos entrevistados: "muda o fiscal, muda tudo". Além disso, há uma percepção por parte do produtor que busca atender às exigências demandadas de que, por mais que proceda a alterações, "nunca é suficiente" para receber aprovação. Existem incertezas relacionadas a mudanças frequentes na inspeção ou nas legislações. Em função disso os técnicos da extensão rural também não têm segurança nas orientações que repassam aos produtores em relação aos aspectos legais.

O nível de escolaridade dos produtores, a falta de hábito de registros e de autocontroles; a falta de controle das questões sanitárias do rebanho, das condições de ordenha e de fabricação foram destacados, pelos fiscais, como limitantes. As dificuldades também se verificam na deficiência de capacitação dos produtores, não apenas em Boas Práticas Agropecuárias e Boas Práticas de Fabricação, mas também no entendimento dos processos que atribuem características qualitativas aos queijos, sendo também importante capacitá-los no processo de maturação.

Nas entrevistas, alguns produtores afirmaram que a concorrência de preços dos produtores formalizados com os produtores não formalizados constitui dificuldade, assim como o fato de o produtor ainda não ter encontrado mercado consumidor que reconheça QAS como produto diferenciado. Em relação à comercialização do produto, a busca de novos mercados se apresenta como um desafio, o que evitaria que o produtor formalizado concorresse com aquele que não está formalizado, realizando diferencial por qualidade, e não por preço.

Outra dificuldade abordada pelos produtores foi a questão sanitária, especialmente em relação à exigência de as propriedades onde se produz QAS serem certificadas como livres de brucelose e tuberculose. Em caso de diagnóstico positivo para estas enfermidades, a propriedade fica interditada e o animal deve ser abatido. Quando um produtor rural comercializa leite in natura para a indústria, ou carne para o frigorífico, tem uma garantia de ressarcimento financeiro por animal via Fundo de Desenvolvimento e Defesa Sanitária Animal (FUNDESA) através do recolhimento de contribuição sobre as notas fiscais emitidas. Já o produtor de QAS geralmente não se enquadra em nenhuma destas duas categorias, ficando excluído da possibilidade de ressarcimento. Esta falta de amparo necessita atenção do poder público. $O$ que se percebe é que os poucos produtores que estão realizando a certificação de suas propriedades como livre de brucelose e tuberculose estão cientes do não ressarcimento pelo FUNDESA, e uma discussão sobre o tema com 
os órgãos responsáveis não parece ser uma demanda, devido à falta de informação dos produtores sobre o assunto.

\subsection{ACCÕES DE INSTITUIÇÕES PARA ASSISTÊNCIA AOS PRODUTORES DE QUEIJO ARTESANAL SERRANO}

Como exemplos de instituições de ensino e/ou pesquisa com envolvimento no sistema agroalimentar do QAS foram citados agentes do governo federal (MAPA, Secretaria Especial de Agricultura Familiar e do Desenvolvimento Agrário - SEAD), estadual (SEAPI, SDR e Fundação Estadual de Pesquisa Agropecuária - Fepagro, atual DDPA-SEAPDR) e municipal (Secretarias de agricultura) bem como universidades (Universidade Federal do Rio Grande do Sul - UFRGS, Universidade Estadual do Rio Grande do Sul - UERGS, Universidade Luterana do Brasil - ULBRA, Universidade de Caxias do Sul - UCS) e empresas de assistência técnica e extensão rural (Emater/RS e Epagri).

Em relação a instituições que apresentam ação direta com a produção de QAS, a Emater/RS foi a entidade citada por unanimidade por todos os grupos entrevistados. Em menor medida, também foram mencionados o envolvimento do governo federal (MAPA, MDA e SEAD), estadual (SEAPI, SDR, Federação das Associações de Municípios do Rio Grande do Sul - FAMURS) e municipal (Secretarias de agricultura) e das Associações (Aprocampos, Aprojac e Aprosãochico). Outras instituições que pontualmente citadas como agentes no sistema agroalimentar do QAS foram Vigilância Sanitária dos municípios, o Ministério Público, os Sindicatos Rurais, os Sindicatos dos Trabalhadores Rurais, SEBRAE, SENAR, o Colegiado de Desenvolvimento Territorial (CODETER) e agentes de crédito (FEAPER, Banco do Brasil, SICREDI).

Outras iniciativas relatadas foram rodas de discussão sobre o QAS em grupos de secretários de agricultura dos municípios, assim como em reuniões de prefeitos na Associação dos Municípios dos Campos de Cima da Serra (Amucser), durante encontros do Consórcio Intermunicipal de Desenvolvimento Sustentável da Região dos Campos de Cima da Serra (Condesus), além de reuniões entre os veterinários dos SIM dos municípios para discussão de legislação referente ao QAS.

Mesmo havendo menção de diversas organizações, percebe-se falta de articulação entre elas, falta de um programa conjunto de pesquisa, desenvolvimento e inovação. Pensando no QAS como um vetor de desenvolvimento local, seria necessário estabelecer ações conjuntas e sinérgicas, com uma visão coletiva acerca de suas potencialidades. Faz-se necessário estabelecer uma argumentação que sensibilize os atores locais, e a elaboração de um planejamento conjunto, detalhando a participação de cada organização envolvida - poder público, associações de produtores, academia, instituições de pesquisa e desenvolvimento, agentes de turismo e outros setores da economia que podem se beneficiar de um projeto de desenvolvimento territorial.

\subsection{PAPEL DAS ASSOCIAÇÕES DE PRODUTORES DE QUEIJO ARTESANAL SERRANO}

A organização coletiva de produtores de QAS, em forma de associações, é fundamental como direcionamento de demandas com o poder público e posicionamento frente aos mercados. Além disso, facilita a ação das demais instituições que apoiam o QAS, tecnicamente multiplica o efeito do trabalho com produtores. Em termos políticos, as associações são a representação formal de um conjunto de produtores, legitimando demandas. Determinados processos nem 
podem ser conduzidos sem contar com essa representação, como por exemplo o processo de Indicação Geográfica. Na discussão em torno de arcabouços legais também a presença de associações de produtores fortalece os pleitos.

Em todos os municípios participantes do estudo, há formalização de associações de produtores de QAS: Aprocampos em Bom Jesus e São José dos Ausentes, Aprojaq em Cambará do Sul e Jaquirana e Aprosãochico em São Francisco de Paula. Todas elas fazem parte da Federação de Produtores de Queijo Artesanal Serrano (Faproqas), juntamente com produtores catarinenses. Sobre as ações destas associações nos seus municípios, foram citadas reuniões mensais, contratação conjunta de responsável técnico, participação na regulamentação do QAS, aquisição conjunta de insumos, participação em eventos para comercialização dos produtos e em concursos de queijos.

Entre técnicos e fiscais, muitos afirmaram ter a sensação de que há mais boa vontade entre eles para ações de desenvolvimento, do que entre os próprios produtores de QAS. Isto é justificado pelo aparente desinteresse de maioria dos produtores em formalizarem sua produção, sob a alegação de insegurança legal e econômica. Segundo os técnicos, os produtores também apresentam resistência à participação em cursos de capacitação e em organizações coletivas através das associações. A situação de envelhecimento dos produtores e a falta de sucessão podem explicar o desinteresse pela profissionalização e investimentos na atividade

A autonomia das associações de produtores se apresenta como ponto importante na ativação de um SIAL. Entretanto, no SIAL analisado, se observa que esse é um ponto frágil, já que as associações parecem dependentes de instituições externas. A autonomia geraria maior segurança para uma sequência de atividades. Esta dependência e falta de empoderamento dos produtores refletem na forma passiva do SIAL do QAS.

\subsection{QUEIJO ARTESANAL SERRANO COMO PATRIMÔNIO PRODUTIVO E SUA DIVULGAÇÃO}

Sobre eventos com enfoque na promoção do QAS, desenvolvidos a partir do ano de 2012, os concursos fazem parte de uma metodologia de extensão para divulgação, além de motivação dos produtores quanto à melhoria da qualidade de seus queijos. O primeiro concurso de QAS realizado na região, denominado "Concurso Municipal do Autêntico Queijo Artesanal Serrano", foi em São Francisco de Paula, organizado pela Emater/RS no ano de 2012. A partir de então outros foram realizados, na Festa da Gila e do Queijo Serrano em Bom Jesus, Festa do Município em São José dos Ausentes e Festa do Pinhão em Muitos Capões. Já houve participação do produto durante o evento Mesa São Paulo, e no concurso dos Queijos Artesanais do Brasil, com premiações

Eventos com possibilidade de comercialização do QAS foram a Festa do Pinhão, em São Francisco de Paula, Festa da Gila e do Queijo Serrano em Bom Jesus, Festa do Gaúcho em Jaquirana. Durante a Expointer, em Esteio, no Pavilhão da Agricultura Familiar, a Aprocampos participou com comercialização de seus produtos nos anos de 2012, 2013, 2015 e 2016.

Foram realizados seminários interestaduais de Queijo Serrano entre RS e SC, através de parceria entre Emater/RS e Epagri. Além destes o queijo também foi apresentado, sob diferentes enfoques nas três edições do Seminário dos Queijos Artesanais do Brasil, realizados em Fortaleza/CE, Porto Alegre/RS e Belo Horizonte/MG. Em 2018 foi realizado o Seminário de Queijos Artesanais, incluindo a temática do QAS, aberto ao público, dentro das atividades da Expointer em Esteio/RS, assim como Seminário Técnico em São Francisco de Paula para 
divulgação do projeto de "Qualificação da Cadeia Produtiva do QAS", este último voltado a gestores municipais da região de abrangência do projeto e técnicos do MAPA, SDR, Emater/RS e prefeituras municipais. Neste mesmo ano aconteceu no Espaço Cultural dos Correios em Porto Alegre/RS, o lançamento do livro "Queijo Artesanal Serrano: identidade cultural nos Campos de Cima da Serra" (WAGNER et al., 2018), juntamente com uma exposição fotográfica sobre o tema. Esta mesma exposição fotográfica foi apresentada de modo itinerante em São Francisco de Paula, Vacaria e Gramado, no RS.

Observa-se assim uma gama de eventos que deram destaque ao QAS, além de o acesso à informações pela internet ter aumentado vertiginosamente nos últimos anos. De acordo com a fala de um técnico de extensão rural: "[...] antes, quando digitávamos Queijo Artesanal Serrano em algum site de busca pela internet, apareciam somente informações sobre o Queijo Minas Artesanal, hoje já temos uma grande lista de informações" específicas sobre o QAS. Isso tem colocado o produto em uma situação de maior notoriedade.

\section{SIAL DO QUEIJO ARTESANAL SERRANO NO DECORRER DOS ÚLTIMOS 10 ANOS, ALGUMA MUDANÇA?}

A partir do trabalho de Ambrosini (2007), foi realizado um comparativo sobre eventuais mudanças ocorridas no SIAL do QAS no decorrer dos últimos 10 anos. Mesmo que a legislação vigente apareça, segundo nossos resultados, como um ponto que demande ajustes, percebemos que houve avanços quanto à regulamentação. No RS, foi publicada a Portaria no 214 , de 14 de dezembro de 2010, que dispõe sobre o processo de produção do Queijo Serrano (RIO GRANDE DO SUL, 2010). De acordo com Ries et al. (2013), pela primeira vez no Estado se admitiu legalmente a possibilidade de produção de queijo a partir de leite cru com a publicação desta Portaria, que definiu as características do QAS e delimitou a região produtora. Em 2014, esta portaria foi revogada e substituída pela Portaria SEAPPA no 44 de 21 de março de 2014, que posteriormente foi retificada pela Portaria no 55 de 28 de março de 2014, considerando o grande número de agroindústrias produtoras de queijos artesanais com processamento de até 250 litros por dia e a dificuldade destes estabelecimentos se adequarem às exigências das normas sanitárias até então em vigor, criando nova regulamentação para todas as micro queijarias no RS - não apenas para o QAS (RIO GRANDE DO SUL, 2014a; 2014b).

A IN no 07, da Secretaria de Estado da Agricultura, Pecuária, e do Agronegócio (SEAPA), de 09 de dezembro de 2014, aprovou o Regulamento Técnico de Identidade e Qualidade do Queijo Serrano ou Queijo Artesanal Serrano, definindo-o como um queijo semi gordo de média umidade, produzido a partir de leite cru de bovinos (RIO GRANDE DO SUL, 2014c). Por meio dela também se definiu o QAS como produto maturado que se obtém por coagulação enzimática do leite cru, através da utilização de coalhos industriais, que sofreu as transformações bioquímicas e físicas necessárias à obtenção das características típicas do queijo, considerando-se como ingredientes obrigatórios na composição do QAS: leite integral, coalho e cloreto de sódio, não sendo permitida a adição de outros ingredientes que não os obrigatórios.

Em 29 de dezembro de 2016, foi aprovada, pela Assembleia Legislativa do Estado do RS, a Lei no 14.973, que dispôs sobre a produção e a comercialização do QAS (RIO GRANDE DO SUL, 2016). Em 2018, ocorreu a regulamentação dessa lei, através do Decreto $n^{\circ} 54.199$ de 24 de agosto de 2018 (RIO GRANDE DO SUL, 2018). 
Quanto à organização social de produtores de QAS, em 2001 houve a criação da Associação de Produtores de Leite e Derivados dos CCS, que perdeu força ao longo do tempo, sendo desativada, assim como a Associação da Agroindústria de Queijo Serrano da Criúva, criada em 2004. Em 2010 ocorreu a fundação da Aprocampos. Posteriormente a fundação da Aprojaqui, da Acamproqas, e da Aprosãochico. Em 2017 foi fundada a Federação de Produtores de QAS (Faproqas). Em 2018 houve a fusão da Aprojaqui e Acamproqas formando a Aprojac.

No decorrer do período também foi percebida uma valorização do produto, o valor pago por quilo passou de $R \$ 4,00$ para $R \$ 12,00$ no verão e de $R \$ 7,00$ para $R \$ 18,00$ no inverno, variação maior que a inflação verificada entre 2007 e 2018 , que foi de $68,9 \%$. Vale salientar que registramos, no momento da pesquisa, produtores recebendo até $\mathrm{R} \$ 50,00$ por quilo, sendo esse um QAS maturado por mais de 60 dias. Ainda, a concentração da produção do QAS é maior no verão, período de maior oferta de alimentação (campo nativo) para o gado, gerando uma maior disponibilidade do produto. O inverno marca um período de maior escassez, valorizando seu preço no mercado.

Quanto ao processo de Indicação Geográfica, ele se inicia 2006 a partir do "Projeto Queijo Serrano", com o objetivo de produzir pesquisas acerca do QAS e, posteriormente, avaliar a viabilidade de obter-se uma IG para o produto. Em maio de 2013, a Faproqas, assessorada pela Emater/RS e Epagri, foi responsável pelo encaminhamento do pedido de Registro do saber-fazer do Queijo Serrano como Patrimônio Cultural de Natureza Imaterial, junto ao IPHAN. A demanda visava o reconhecimento da importância cultural deste produto, possibilitando a elaboração de políticas de salvaguarda que preservassem este saber-fazer (RIES et al., 2013). O pedido de registro de IG do QAS foi entregue ao INPI em agosto de 2017, tendo sido aprovado em março de 2020 (BRASIL, 2020).

Quanto às relações interinstitucionais, o contato dos produtores com instituições de pesquisa, ensino e outras entidades privadas ou públicas não influenciavam a atividade de queijaria, sendo que o único apoio recebido por alguns produtores seriam ações da Emater/RS. No decorrer do período analisado, outras instituições passaram a participar de ações relacionadas ao QAS.

Em relação ao acesso à crédito, atualmente, além do Programa Nacional de Fortalecimento da Agricultura Familiar (PRONAF), outras linhas de crédito para os produtores de QAS foram disponibilizadas. O PRONAF foi instituído oficialmente através do Decreto Presidencial № 1.946, de 28 de junho de 1996 (BRASIL, 1996), concebido com a finalidade de apoiar o desenvolvimento rural. Seu fundamento está no fortalecimento da agricultura familiar como segmento gerador de emprego e renda (AQUINO; SCHNEIDER, 2015), por meio do financiamento de atividades e serviços rurais agropecuários e não agropecuários desenvolvidos em estabelecimento rural ou em áreas comunitárias próximas.

Parte dos produtores de QAS se enquadra nas exigências estabelecidas pelo PRONAF, contudo em relação ao quesito área da propriedade (até quatro módulos fiscais), alguns são excluídos desta política pública. Dentre os produtores de QAS do RS, a maior parte destes se enquadra na categoria de pecuarista familiar, tipificação regulamentada pelo Programa Estadual de Desenvolvimento da Pecuária de Corte Familiar (PECFAM), instituída pela Lei $\mathrm{n}^{\circ}$ 13.515, de 13 de setembro de 2010 (RIO GRANDE DO SUL, 2010), regulamentada pelo Decreto $\mathrm{n}^{\circ}$ 48.316, de 31 de agosto de 2011 (RIO GRANDE DO SUL, 2011). Neste enquadramento os produtores têm direito a acessar recurso de financiamento estatal via Fundo Estadual de Apoio ao Desenvolvimento dos Pequenos Estabelecimentos Rurais (FEAPER), desde que cadastrados no Programa Estadual de Agroindústria 
Familiar (PEAF), criado pela Lei Estadual oㅜ 13.921, de 17 de janeiro de 2012, e regulamentado pelo Decreto Estadual no 49.341 de 5 de julho 2012 (ESTADO DO RIO GRANDE DO SUL, 2012a; 2012b). Segundo dados da Emater/RS, a maioria das agroindústrias de QAS cadastradas no PEAF já acessaram recursos via FEAPER, principalmente para construção das queijarias e aquisição de equipamentos, recebendo $80 \%$ de abatimento no pagamento do financiamento se as parcelas forem quitadas dentro do prazo estabelecido em contrato.

Em função de sua organização, a Aprocampos viabilizou a escolha do QAS pelas agências do Banco do Brasil de Bom Jesus, São José dos Ausentes e Jaquirana, como produto prioritário para o desenvolvimento de um Projeto de Desenvolvimento Rural Sustentável em 2013, o que proveu aporte de recursos financeiros para capacitações, aquisição de materiais de construção e equipamentos para qualificação do produto final pela Fundação Banco do Brasil.

Em relação ao aporte de recursos para projetos de pesquisa, em 2006 foi estabelecido convênio com o MAPA e MDA, que possibilitou a realização de um diagnóstico a partir de entrevistas com os produtores de QAS. O resultado foi uma caracterização realizada pelos extensionistas da Emater/RS e da Epagri em relação aos procedimentos utilizados na produção do queijo e algumas análises laboratoriais realizadas durante o desenvolvimento desse projeto, intitulado "Realização de pesquisa sobre o Queijo Artesanal Serrano produzido pelos pecuaristas familiares dos Campos de Cima da Serra no Rio Grande do Sul". Em 2017 o projeto denominado "Qualificação da Cadeia Produtiva do Queijo Artesanal Serrano" foi desenvolvido através de convênio entre o MAPA e a SDR no RS. ,Parte das atividades foram executadas pela Emater/RS com o objetivo de acompanhar 50 queijarias, qualificar produtores, através de capacitações; realizar visitas de acompanhamento nas propriedades e promover ferramentas de autocontrole da produção da matéria prima e produto final, além de realizar análises laboratoriais durante a vigência do projeto, com previsão de três anos de execução. Comprovar a possibilidade da redução do tempo legal de maturação deste produto se apresenta como um dos principais objetivos deste trabalho. A Tabela 2 apresenta o resumo de transformações percebidas neste período. 
TABELA 2 - Transformações ocorridas no SIAL do QAS no período entre 2008 e 2018.

\begin{tabular}{|c|c|c|}
\hline & Anterior a 2007 & 2008 a 2018 \\
\hline $\begin{array}{l}\text { Legislação específica } \\
\text { QAS }\end{array}$ & Ausente & $\begin{array}{l}\text { Portaria } 214 / 2010 \\
\text { Portaria } 44 / 2014 \\
\text { Portaria } 55 / 2014 \\
\text { IN } 07 / 2014 \\
\text { Lei } 14.973 / 2016 \\
\text { Decreto } 54.199 / 2018\end{array}$ \\
\hline $\begin{array}{l}\text { Organização social } \\
\text { produtores de QAS }\end{array}$ & $\begin{array}{l}\text { 2001- Criação da Associação } \\
\text { de Produtores de Leite e } \\
\text { Derivados dos CCS. } \\
\text { 2004- Associação da } \\
\text { Agroindústria de Queijo } \\
\text { Serrano da Criúva. }\end{array}$ & $\begin{array}{l}2010 \text { - Fundação da } \\
\text { Aprocampos. Posteriormente } \\
\text { também da Aprojaqui, } \\
\text { Acamproqas e Aprosãochico. } \\
\text { 2017-Fundação Faproqas. } \\
\text { 2018- Fusão da Aprojaqui e } \\
\text { Acamproqas formando a } \\
\text { Aprojac. }\end{array}$ \\
\hline $\begin{array}{l}\text { Preço mais baixo pago } \\
\text { pelo kg do queijo }\end{array}$ & $\begin{array}{l}\mathrm{R} \$ 4,00 \text { no verão e } \mathrm{R} \$ 7,00 \\
\text { no inverno. }\end{array}$ & $\begin{array}{l}\mathrm{R} \$ 12,00 \text { no verão e } \mathrm{R} \$ \\
\mathrm{R} \$ 18,00 \text { no inverno }\end{array}$ \\
\hline Indicação Geográfica & 2006- Projeto Queijo Serrano & $\begin{array}{l}\text { 2017- Registro de pedido de } \\
\text { IG entregue ao INPI }\end{array}$ \\
\hline Relações institucionais & Produtores e Emater/RS. & $\begin{array}{l}\text { Produtores, Emater/RS, } \\
\text { MAPA, SDR, universidades, } \\
\text { entre outros. }\end{array}$ \\
\hline Acesso a crédito & Pronaf & $\begin{array}{l}\text { Pronaf/ FEAPER/ Fundação } \\
\text { BB }\end{array}$ \\
\hline $\begin{array}{l}\text { Aporte de recurso } \\
\text { projeto de pesquisa }\end{array}$ & $\begin{array}{l}\text { 2006- Convênio MAPA/ } \\
\text { MDA: "Realização de } \\
\text { pesquisa sobre o QAS } \\
\text { produzido pelos pecuaristas } \\
\text { familiares dos CCS do RS". }\end{array}$ & $\begin{array}{l}\text { 2017- Convênio MAPA/SDR: } \\
\text { "Qualificação da Cadeia } \\
\text { Produtiva do QAS" }\end{array}$ \\
\hline
\end{tabular}

Fonte: Dados da Pesquisa

Percebemos que os desafios ainda são numerosos, mas é inegável que a o QAS ganhou visibilidade e tem despertado o interesse crescente por parte de instituições públicas e da sociedade civil. Iniciativas visando sua valorização, bem como valorizando o modo de vida dos produtores foram empreendidas. Entretanto, percebe-se que ainda há necessidade de aprimorar os processos de concertação dos diferentes atores.

\section{CONSIDERAÇÕES FINAIS}

Este trabalho partiu da motivação de compreender as relações entre os atores envolvidos na produção do QAS, buscando entender os principais entraves para o desenvolvimento deste SIAL.

A dimensão institucional do SIAL do QAS apresentou multiplicidade de atores envolvidos, com diferentes funções e relações, envolvendo produtores individuais ou organizados em associações, intermediários, pontos de comércio, consumidores (relações verticais), além de gestores, legisladores, técnicos da extensão, fiscais sanitários e pesquisadores (relações horizontais). Analisando a relação dos diferentes atores, percebe-se baixo grau de coordenação. Em diversas situações, seus posicionamentos se antagonizam, não havendo consonância sobre as particularidades que valorizariam o produto. Ainda, questões legais determinam 
conflitos entre os atores envolvidos nas relações de produção, comercialização, regulamentação e consumo, impactando na ativação do SIAL do QAS.

A simplificação da legislação, a coerência de interpretação e ação por parte dos agentes de inspeção, além de desenvolvimento de uma planta padrão simples para agroindústria que possa servir para a maioria dos produtores são sugestões para atender demandas dos produtores. Há ainda a necessidade melhorar a comunicação, simplificando a linguagem técnica empregada pelos agentes públicos.

O diálogo com atores ligados ao SIAL do QAS contribuiu para a compreensão do território dos cinco municípios, objeto deste estudo, e pode servir como base para desenvolvimento de estratégias para avanço nas relações entre os atores através de trabalhos educativos e participativos. A mobilização coletiva em torno do QAS permanece frágil, levando à definição de SIAL do QAS como um SIAL na forma passiva.

O Queijo Serrano representa o sustento de um número expressivo de famílias dos Campos de Cima da Serra, além de estar intimamente ligado à sua identidade cultural, constituindo um patrimônio dos produtores. Seu saber-fazer, passado de geração a geração, tem se mantido através de estratégias coletivas, mesmo que de forma ainda frágil, mas com mudanças no decorrer do tempo. O reconhecimento pelo mercado consumidor vai além das questões legais estabelecidas, sendo uma relação de memória afetiva e preservação da história local, um alimento vivo que nutre não somente o corpo, mas a alma do serrano.

\section{REFERÊNCIAS}

AMBROSINI, L. B. Sistema agroalimentar do queijo serrano: estratégia de reprodução social dos pecuaristas familiares dos Campos de Cima da Serra- RS. 2007. 194f. Dissertação (Mestrado em Desenvolvimento Rural) - Programa de PósGraduação em Desenvolvimento Rural, Universidade Federal do Rio Grande do Sul.

AMBROSINI, L. B.; FILIPPI, E. E. Sistema Agroalimentar do Queijo Serrano: Estratégia de Reprodução Social dos Pecuaristas Familiares no Sul do Brasil. In: CONGRESSO INTERNACIONAL DE LA RED SIAL, 4., 2008, Mar del Plata, Argentina. Anais... Mar del Plata, Argentina: Rede SIAL, 2008. p. 1-24.

AQUINO, J. R.; SCHNEIDER, S. O Pronaf e o desenvolvimento rural brasileiro: avanços, contradições e desafios para o futuro. In: GRIZA, C.; SCHNEIDER, S. (Org.). Políticas públicas de desenvolvimento rural no Brasil. Porto Alegre: Editora da UFRGS, 2015.

BOM JESUS. Lei no 1777, de 11 de outubro de 1995. Dispõe sobre a Inspeção Sanitária e Industrial dos Produtos de Origem Animal e dá Outras Providências.

BRASIL. Decreto no 1946, de 28 de junho de 1996. Cria o Programa Nacional de Fortalecimento da Agricultura Familiar - Pronaf, e dá outras providências. Diário Oficial [da] República Federativa do Brasil, Brasília, DF, 01 jul. 1996.

BRASIL. INSTITUTO NACIONAL DA PROPRIEDADE INDUSTRIAL. Indicações Geográficas. Seção IV. Revista da Propriedade Industrial, n. 2565, 03 mar. 2020. 
BOUCHER, F. Sistemas Agroalimentarios Localizados (SIAL), una nueva visión de gestión territorial en América Lat: experiencias en territorios de Argentina, Costa Rica, Ecuador y México. Mexico: lica, 2013.

CONCEIÇÃO, O. A. C. O conceito de instituição nas modernas abordagens institucionalistas. Revista de Economia Contemporânea, v. 2, n. 6, p.119-146, jul. 2002.

CAMBARÁ DO SUL. Lei no 2053, de 09 de junho de 2004. Dispõe sobre a Inspeção Sanitária e Industrial de Produtos de Origem Animal e dá Outras Providências.

CÓRDOVA, U. A. et al. Queijo Artesanal Serrano: séculos de travessia de mares, serras e vales - a história nos campos da Serra Catarinense. Florianópolis: Epagri, 2010.

CRUZ, F. T.; SANTOS, J. S. Alimentos tradicionais, modos de vida e desenvolvimento rural: um estudo a partir do Queijo Serrano dos Campos de Cima da Serra, Rio Grande do Sul. In: WAQUILL, P.D. et al. Pecuária Familiar no Rio Grande do Sul: história, diversidade social e dinâmicas de desenvolvimento. Porto Alegre: UFRGS, 2016.

FRANÇA, O.E. O caso Queijo do Serro como Sistema Agroalimentar Local SIAL: complementaridade entre produção agroalimentar e turismo. 2012. $178 \mathrm{f}$. Dissertação (Mestrado em Agronegócios) - Programa de Pós-graduação em Agronegócios, Universidade de Brasília.

FÜHR, A. L. et al. A agroindústria familiar e as regulamentações sanitárias: análise da aplicabilidade da resolução 49/2013 em um município do sudoeste do Paraná. Extensão Rural, Santa Maria, v.26, n.4, p.69-89, out./dez. 2019. Disponível em: https://periodicos.ufsm.br/extensaorural/article/view/34490. Acesso em: $10 \mathrm{dez}$. 2018.

JAQUIRANA. Lei no 1192, de 21 de junho de 2016. Dispõe sobre a Inspeção Industrial e Sanitária dos Produtos de Origem Animal.

KRONE, E.E.; MENASCHE, R. Identidade e Cultura nos Campos de Cima da Serra (RS): práticas, saberes e modos de vida de pecuaristas familiares produtores do Queijo Serrano. Ateliê Geográfico, v. 4, n. 10, abr. 2010.

LASCOUMES, P.; GALÈS, P. L. Sociologia de la accion publica. 2. ed. Mexico, D.f: El Colegio de Mexico, 2014.

MUCHNIK, J. Sistemas agroalimentarios localizados: evolución del concepto y diversidad de situaciones. In: CONGRESO INTERNACIONAL DE LA RED SIAL"ALIMENTACIÓN Y TERRITORIOS", 3., 2006, Baeza (jaén), España. Anais... Baeza (jaén), España: Alter, 2006. p. 1 - 21.

MUCHNIK, J. et al. Les Systèmes agroalimentaires localisés (SYAL). Économies et Sociétés - Série Systèmes Agroalimentaires, n. 29, p.1465-1484, set. 2007. 
NORTH, D. C. Institutions, Institutional Change and Economic Performance. Cambridge: Cambridge University Press, 1990.

STRECK, E. V. et al. Solos do Rio Grande do Sul. 3. ed. Porto Alegre: Emater/RSAscar, 2018.

REQUIER-DESJARDINS, D. L'évolution du débat sur les SYAL : le regard d'un économiste. Revue D'Économie Régionale \& Urbaine, n. 4, p.651-668, out. 2010.

RIES, J. E. et al. Projeto de qualificação e certificação do queijo serrano produzido nos Campos de Cima da Serra do Rio Grande do Sul - relato parcial da experiência. Agroecologia e Desenvolvimento Rural Sustentável, v. 5, n. 1, p. 10-19, jan./abr. 2012

RIES, J. E. et al. Aprocampos: uma experiência de sucesso na qualificação e valorização do queijo artesanal serrano. In: FEDERACITE, Federacite, p. 50-61, 2013.

RIO GRANDE DO SUL. Lei no 11.179, de 25 de junho de 1998. Dispõe sobre a consulta direta à população quanto à destinação de parcela do Orçamento do Estado do Rio Grande do Sul voltada a investimentos de interesse regional. Diário Oficial do Estado do Rio Grande do Sul, Porto Alegre, RS, 26 jun. 1998.

RIO GRANDE DO SUL. Lei no 13.515, de 13 de setembro de 2010. Institui o Programa Estadual de Desenvolvimento da Pecuária de Corte Familiar e dá outras providências. Diário Oficial do Rio Grande do Sul, Porto Alegre, RS, 14 set. 2010.

RIO GRANDE DO SUL. Portaria no 214, de 14 de dezembro de 2010. Aprova o Regulamento Técnico para fixação de Identidade e Qualidade do Queijo Serrano ou Queijo Artesanal Serrano e dá outras providências. Porto Alegre, RS, 14 dez. 2010.

RIO GRANDE DO SUL. Decreto no 48.316, de 31 de agosto de 2011. Regulamenta o Programa Estadual de Desenvolvimento da Pecuária de Corte Familiar - PECFAM, instituído pela Lei no 13.515 , de 13 de setembro de 2010, e dá outras providências. Diário Oficial do Estado do Rio Grande do Sul, Porto Alegre, RS, 1ํo set. 2011.

RIO GRANDE DO SUL. Lei no 13.921, de 17 de janeiro de 2012. Institui a Política Estadual de Agroindústria Familiar no Estado do Rio Grande do Sul. Diário Oficial do Estado do Rio Grande do Sul, Porto Alegre, RS, 18 jan. 2012a.

RIO GRANDE DO SUL. Decreto no 49.341, de 05 de julho de 2012. Cria o Programa de Agroindústria Familiar do Estado do Rio Grande do Sul, institui o Selo de Marca de Certificação "Sabor Gaúcho" e dá outras providências. Diário Oficial do Estado do Rio Grande do Sul, Porto Alegre, RS, 06 jul. 2012b.

RIO GRANDE DO SUL. Portaria no 44 de 21 de março de 2014. Estabelece Norma Técnica relativa à instalação e equipamentos para micro queijarias no Estado do Rio Grande do Sul. Porto Alegre, RS, 24 mar. 2014a.

RIO GRANDE DO SUL. Portaria no 55 de 28 de março de 2014. Retifica a Portaria Seappa № 44 de 2014, que estabelece Norma Técnica relativa a instalação e equipamentos. Porto Alegre, RS, 31 mar. 2014b. 
RIO GRANDE DO SUL. Instrução Normativa no 07, de 9 de dezembro de 2014. Aprova o Regulamento Técnico de Identidade e Qualidade do Queijo Serrano. Diário Oficial do Estado do Rio Grande do Sul, Porto Alegre, RS, 10 dez. 2014c.

RIO GRANDE DO SUL. Lei no 14.973, de 29 de dezembro de 2016. Dispõe sobre a produção e a comercialização do queijo artesanal serrano no Estado do Rio Grande do Sul. Diário Oficial do Estado do Rio Grande do Sul, Porto Alegre, RS, 30 dez. 2016.

RIO GRANDE DO SUL. Resolução no 17, de 22 de dezembro de 2017. Aprova as disposições aplicáveis aos contratos de financiamentos pelo Feaper (manual Feaper 2018). Porto Alegre, RS, 27 dez. 2017.

RIO GRANDE DO SUL. Decreto no 54.199, de 24 de agosto de 2018. Regulamenta a lei $n^{\circ} 14.973 / 2016$, que dispõe sobre a produção e a comercialização do Queijo Artesanal Serrano no Estado do Rio Grande do Sul. Porto Alegre, RS, 27 ago. 2018.

RUCKERT, A. A. Políticas territoriais, ciência \& tecnologia e a ação de atores locais e regionais. O Pólo de Modernização Tecnológica da Serra - Rio Grande do Sul Brasil. Sociologias, v. 6, n. 11, p. 148-183, jan/jun. 2004.

SÃO FRANCISCO DE PAULA. Lei no 2.437, de 25 de abril de 2007. Institui o Serviço de Inspeção Municipal dos Produtos de Origem Animal e Vegetal no Município de São Francisco de Paula. São Francisco de Paula, RS.

SÃO JOSÉ DOS AUSENTES. Lei no 733, de $\mathbf{3 0}$ de agosto de 2007. Dispõe sobre a Inspeção e Fiscalização dos Produtos de Origem Animal no Município, cria o Serviço de Inspeção Municipal - S.I.M. - e dá outras providencias.

SPECHT, S. O território do morango no Vale do Caí- RS: análise pela perspectiva dos sistemas agroalimentares localizados. 2009. 317f. Tese (Doutorado em Desenvolvimento Rural) - Programa de Pós-Graduação em Desenvolvimento Rural, Universidade Federal do Rio Grande do Sul.

STRECK, E.V. et al. Solos do Rio Grande do Sul. 3. ed. Porto Alegre: Emater/RSAscar, 2018.

VELHO, J. B. et al. Queijo artesanal serrano: "uma receita passada de geração para geração". Porto Alegre: EMATER/RS- Ascar, 2011.

VIEIRA, V. F.; DORTZBACH, D. Caracterização ambiental e delimitação geográfica dos Campos de Cima da Serra. Florianópolis: Epagri, 2017.

WAGNER, S.A. et al. Queijo artesanal serrano: identidade cultural nos Campos de Cima da Serra. Porto Alegre: Alma da Palavra, 2018. 